\title{
Clinical outcomes of second- versus first-generation drug-eluting stents in patients with acute myocardial infarction: a meta-analysis of randomized controlled trials
}

\author{
Guodong $\mathrm{Wu}^{1}$, Guoqiang Sun ${ }^{1}$, Ruihong Zhao ${ }^{2}$, Mingli Sun ${ }^{3}$
}

\begin{abstract}
1Department of Cardiology, First Hospital of Jilin University, Changchun, China 2Department of Endoscopy and Gastroenterology, First Hospital of Jilin University, Changchun, China

${ }^{3}$ Emergency Department, First Hospital of Jilin University, Changchun, China
\end{abstract}

Submitted: 20 July 2013

Accepted: 18 October 2013

Arch Med Sci 2014; 10, 4: 643-650

DOI: 10.5114/aoms.2014.44855

Copyright $\odot 2014$ Termedia \& Banach

\author{
Corresponding author: \\ Mingli Sun MD \\ Emergency Department \\ First Hospital \\ of Jilin University \\ Ji'lin Road 3302 \\ Changchun 130031, China \\ Phone: +8643188782222 \\ Fax: +8643184896892 \\ E-mail: \\ sunmingli1999@163.com
}

\begin{abstract}
Introduction: It remains unclear whether the clinical outcomes of patients with acute myocardial infarction (AMI) receiving second- and first-generation drug-eluting stents (DES) are identical. The study aimed to investigate the differences in clinical utility between the two generations of DES in these specific subjects by a meta-analysis.

Material and methods: We systemically searched PubMed and EMBASE databases and the Cochrane Library up until January 2013. Randomized trials, which compared clinical outcomes of second-generation DES (everolimus(EES) or zotarolimus-eluting stents (ZES)) with first-generation DES (sirolimus- or paclitaxel-eluting stents) in patients with AMI were included.

Results: Five trials with 1720 AMI subjects were included in the meta-analysis. Pooled analysis demonstrated a trend toward lower incidence of stent thrombosis with the second-generation DES relative to the first-generation one (risk ratio (RR), 0.53 ; $95 \%$ confidence intervals $(\mathrm{Cl}): 0.25-1.13 ; p=0.10$ ). However, the second-generation DES did not offer a significant advantage over the first-generation DES in reducing the incidence of target lesion revascularization (TLR) $(\mathrm{RR}=1.73 ; 95 \% \mathrm{Cl}: 0.83-3.64 ; p=0.15)$, major adverse cardiac events (MACEs) $(R R=0.97 ; p=0.90)$, or all-cause death $(R R=1.00$; $p=1.0)$. In addition, in elderly patients the second-generation DES seemed to reduce the occurrence of MACEs $(\mathrm{RR}=0.65 ; p=0.10)$ and stent thrombosis $(R R=0.40 ; p=0.08)$, and the second-generation EES showed a potential benefit in lowering the MACE rate ( $R R=0.55 ; p=0.06)$.

Conclusions: The second-generation DES appeared to lower the risk of stent thrombosis in AMI patients. There might be a lower incidence of MACEs associated with the second-generation EES.
\end{abstract}

Key words: acute myocardial infarction, second-generation drug-eluting stents, meta-analysis.

\section{Introduction}

A growing number of drug-eluting stents (DES) are used for treatment of acute myocardial infarction (AMI) during primary percutaneous coronary intervention $(\mathrm{PCI})[1,2]$. For these subjects with a highly thrombotic environment, the introduction of DES has greatly alleviated the major problem of in-stent restenosis in the bare-metal stent era [3]. Howev- 
er, the first-generation DES, such as sirolimus- or paclitaxel-eluting stent (SES or PES), have raised the concern for increased stent thrombosis $[4,5]$. A pooled patient-level meta-analysis showed that the first-generation DES (SES and PES) significantly increased the occurrence of stent thrombosis compared with bare-metal stents in patients with AMI [6]. Daemen et al. found that the incidence of early stent thrombosis was similar for SES (1.1\%) and PES (1.3\%), but late stent thrombosis was more frequent with PES $(1.8 \%)$ than with SES (1.4\%) [5]. Late-acquired stent malapposition, incomplete stent endothelialisation, fibrin deposition and persistent inflammation have been suggested as responsible in the pathogenesis of DES thrombosis [1, 7]. The SES-aspirate plasma induced more significant vasoconstriction than PES-aspirate. The favorable effect of PES was possibly secondary to microtubular stabilization, which could be beneficial in preventing a no-reflow phenomenon in patients undergoing stenting [8]. For working out the thrombotic problem, newer antiproliferative drugs (e.g. everolimus) and more biocompatible polymers have shown promise in reducing the rate of stent thrombosis in patients in stable condition $[9,10]$. A large-scale comprehensive network meta-analysis found that the second-generation everolimus-eluting stents (EES) were associated with a reduced 2-year incidence of stent thrombosis in comparison with bare-metal stents and first-generation DES in patients with unrestricted coronary heart diseases [11]. However, it remains unclear whether the clinical outcomes of the newer second-generation DES and the first-generation DES are identical in AMI settings with the higher possible thrombotic coronary lesions.

We therefore performed a meta-analysis on the basis of the available data from randomized controlled trials (RCTs) to investigate the clinical value of second- versus first-generation DES in patients with AMI.

\section{Material and methods}

\section{Search strategy and selection criteria}

We searched PubMed and EMBASE databases, and the Cochrane Central Register of Controlled Trials until January 2013 for eligible trials. The reference list of relevant studies was additionally scanned. No language restriction was imposed. The following search terms were used: "randomized trial", "everolimus", "zotarolimus", "sirolimus", "paclitaxel”, "drug-eluting stent", "acute myocardial infarction", "acute coronary syndrome". To be included, the citation had to meet the following criteria: 1) random treatment allocation; 2) comparisons of second-generation DES (EES or zotaro- limus-eluting stents (ZES)) versus first-generation DES (SES or PES)) which were approved by the US Food and Drug Administration; 3) enrollment of AMI patients; 4) availability of clinical outcomes of definite or probable stent thrombosis, target lesion revascularization (TLR), major adverse cardiac events (MACEs), or all-cause mortality; 5) a mean follow-up period no less than 6 months.

\section{Study identification, quality assessment and data management}

Two investigators assessed trial eligibility independently. Data on participant and procedural characteristics, follow-up duration, and the predefined clinical outcomes were extracted. Any disagreement was resolved through discussion. The initially selected studies were evaluated for quality in accordance with a well-established, validated scale developed by Jadad et al. [12]. The possible range of scores was 0 (weakest) to 5 (strongest).

\section{Statistical analysis}

Review Manager 5.1 software (Cochrane Collaboration, Denmark) was used for meta-analysis. Risk ratio (RR) with 95\% confidence interval (CI) was used as summary statistics. The pooled RR was calculated using the random effects Mantel-Haenszel model. The heterogeneity between selected articles was tested using $R$ statistics $\left(I^{2}\right.$ values $<25 \%$ indicated low, $25-50 \%$ indicated moderate, and $>50 \%$ indicated high heterogeneity [13]). Subgroup analyses were performed according to the type of the second-generation DES, mean age, time from symptom to angioplasty, stent length, and stent size. Sensitivity analyses were conducted by omitting each trial at a time from the analysis to verify the robustness of the overall results. We assessed the possibility of publication bias by visual inspection of funnel plot asymmetry. Statistical significance was set at 2 -tailed $p<0.05$ in the meta-analysis.

\section{Results}

After systemically searching the electronic databases, we identified 5 RCTs comparing clinical outcomes of the second- versus the first-generation DES in patients with AMI (Figure 1). In total, our meta-analysis included data on 1720 patients (Table I). Of the enrolled 5 RCTs [14-18], three studies compared ZES versus the first-generation DES (two for ZES vs. SES vs. PES [14, 18]; one for ZES vs. SES [16]) and the remaining 2 targeted EES versus SES $[15,17]$. Four trials focused on patients with ST-segment elevation AMI [14-16, 18], and one study included $96 \%$ subjects with ST-segment elevation $\mathrm{AMI}$ and $4 \%$ with non-ST-segment elevation AMI [17]. The mean age of enrolled par- 


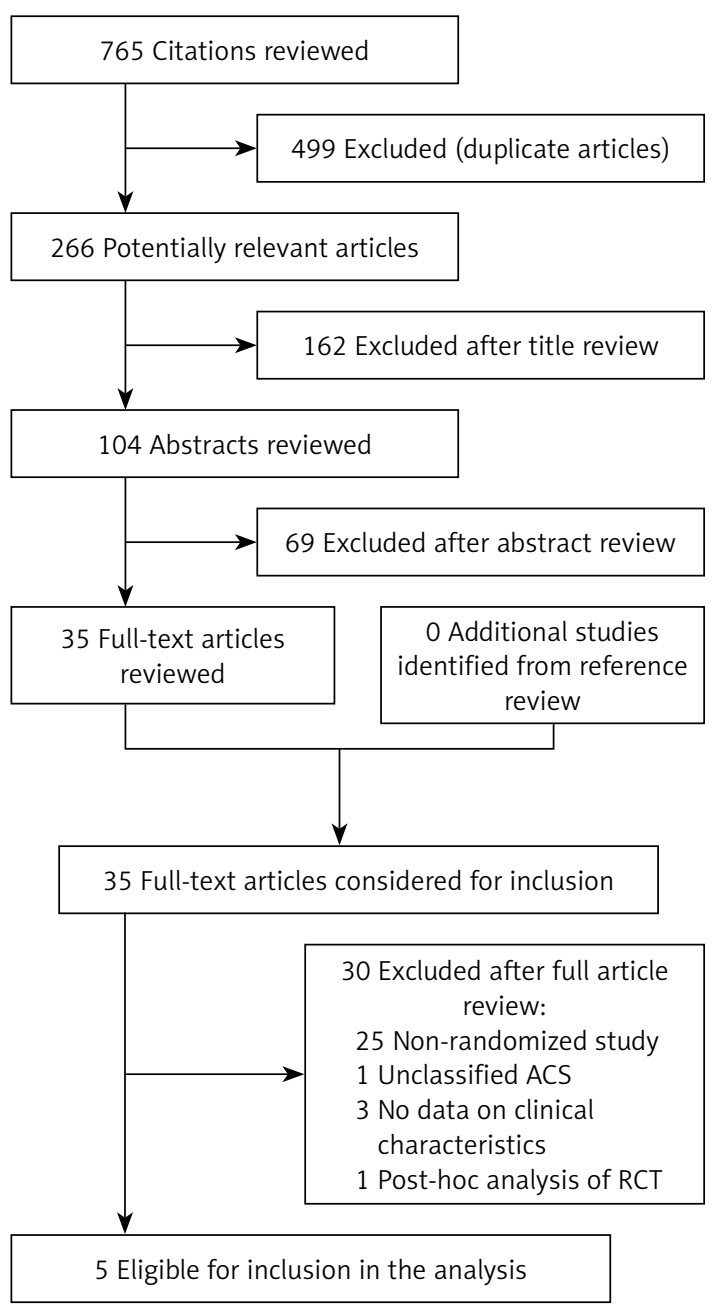

Figure 1. Flowchart of selection of studies for inclusion in meta-analysis

ACS - acute coronary syndrome, RCT - randomized controlled trial

ticipants ranged from 59.7 years to 65.3 years. The mean number of implanted stents per lesion ranged from 1.15 to 1.35 , mean length of stents from $24.1 \mathrm{~mm}$ to $31.6 \mathrm{~mm}$, and mean diameter from $3.14 \mathrm{~mm}$ to $3.27 \mathrm{~mm}$. No differences were observed in medications at discharge in the individual trials. All of the enrolled patients received dual antiplatelet therapy for at least 12 months or to the end of the follow-up. In addition, each study was graded with a score of 3 to 4 according to the Jadad quality score.

Pooling analysis demonstrated that the second-generation DES presented a tendency towards reduced incidence of definite or probable stent thrombosis compared with the first-generation DES (RR $=0.53 ; 95 \% \mathrm{Cl}$ : 0.25-1.13; $p=0.10$; Figure 2). There was no significant heterogeneity across the enrolled trials $\left(l^{2}=0 \% ; p=0.63\right)$. Similarly, the second-generation EES showed a beneficial trend in subgroup analysis $(\mathrm{RR}=0.41, p=0.11$; Table II). However, ZES did not show a potential

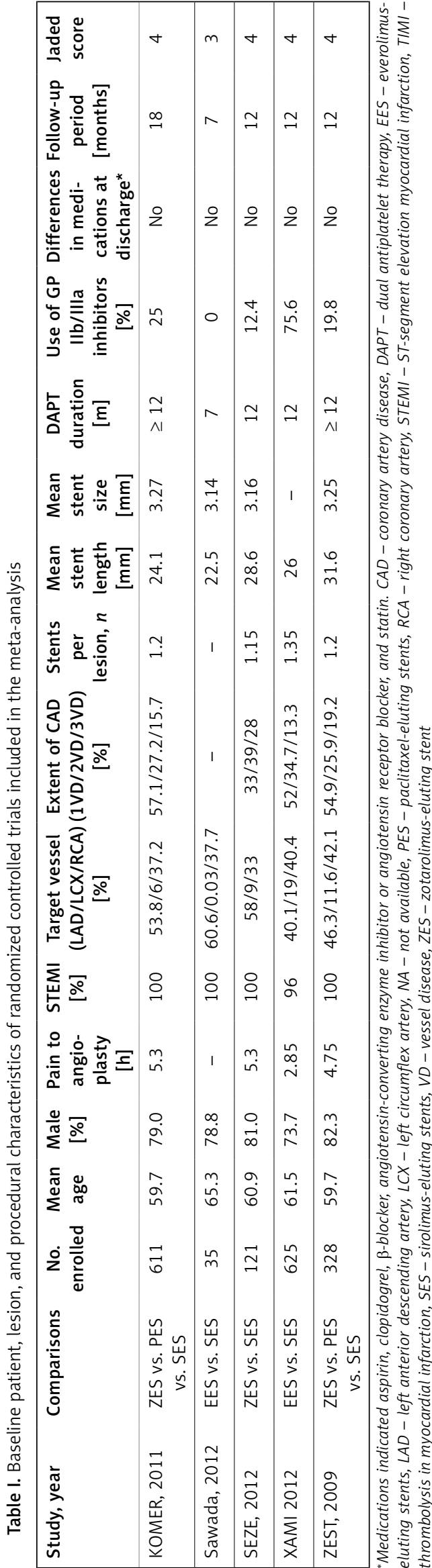




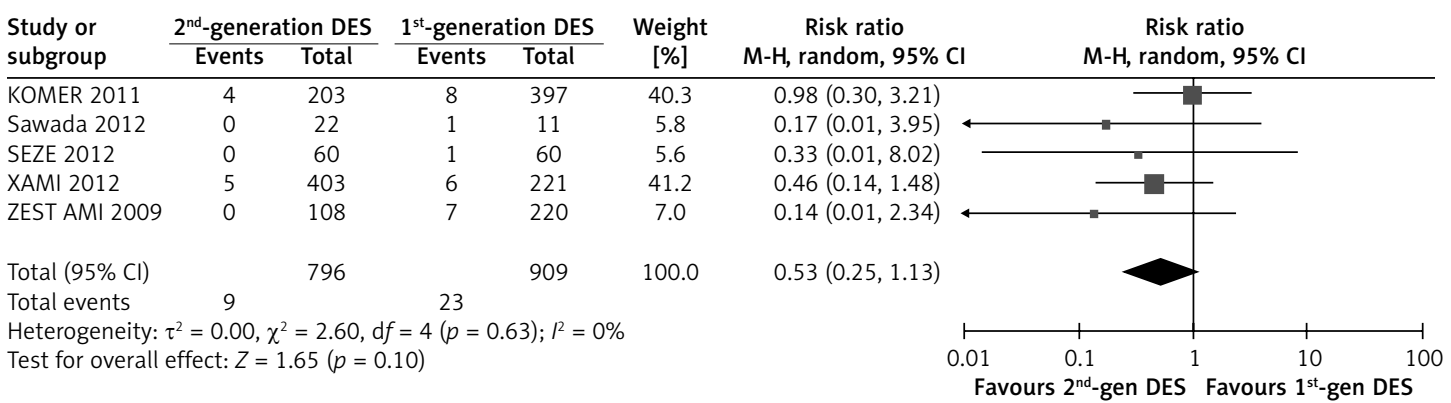

Figure 2. Forest plot of risk ratios of second-versus first-generation drug-eluting stents for stent thrombosis

$\mathrm{Cl}$-confidence intervals, DES - drug-eluting stents, $\mathrm{M}-\mathrm{H}$-Mantel-Haenszel

benefit (Table II). Moreover, subjects aged at least 60 years or receiving primary $\mathrm{PCl}$ within $5 \mathrm{~h}$ from pain to angioplasty seemed to achieve a benefit in lowering the risk of stent thrombosis from the second-generation DES implantation $(\mathrm{RR}=0.40, p=0.08 ; \mathrm{RR}=0.38, p=0.08$, respectively; Table II).

However, the second-generation DES did not provide a significant advantage over the first-generation DES in lowering the incidence of TLR (RR = 1.73; 95\% Cl: 0.83-3.64; $p=0.15 ; R^{2}=0 \%$; Figure 3), MACES $(\mathrm{RR}=0.97 ; 95 \% \mathrm{Cl}: 0.61-1.54 ; p=0.90$ $R^{2}=41 \%$; Figure 4), or all-cause death $(\mathrm{RR}=1.00$; $95 \% \mathrm{Cl}: 0.42-2.36 ; p=1.0 ; P^{2}=28 \%$; Figure 5 ) in AMI patients. However, the occurrence of TLR in the second-generation DES appeared to be higher than that in the first-generation DES in AMI patients aged less than 60 years old or the size of implanted stent more than $3.2 \mathrm{~mm}$ (both $\mathrm{RR}=3.42$; $p=0.05$; Table II). Nevertheless, the second-generation EES might be associated with reduced incidence of MACEs (RR $=0.55 ; p=0.06$; Table II). Due to only 3 trials enrolled in the analysis on all-cause death, we did not perform subgroup analyses on this clinical outcome.

In addition, when the study by KOMER [14] was omitted from the analysis on in-stent thrombosis, the statistical difference of the overall result became significant $(\mathrm{RR}=0.35,95 \% \mathrm{Cl}: 0.13-0.93$, $p=0.04, I^{2}=0 \%$ ). Except for the process, exclusion of any single trial from the analysis did not substantively alter other overall results of our analysis. There were no significant funnel plot asymmetries for all the predefined clinical outcomes, which indicated no publication bias among the enrolled trials in the present study.

\section{Discussions}

In the current study, we performed a meta-analysis of five RCTs in order to elucidate clinical outcomes associated with the second-generation DES and first-generation DES in patients undergoing $\mathrm{PCl}$ for $\mathrm{AMI}$. The main findings revealed that the second-generation DES appeared to reduce the occurrence of definite or probable stent thrombosis in patients with $\mathrm{AMI}$ compared with the first-generation DES. In addition, the use of the second-generation EES seemed to result in a lower occurrence of MACEs than the first-generation DES. Moreover, in elderly patients the second-generation DES showed a trend toward reduced incidence of MACEs and stent thrombosis in patients with AMI. In contrast, the younger patients receiving the second-generation DES implantation might have a higher rate of TLR. Furthermore, the second-generation DES might provide a greater benefit in lowering the risk of in-stent thrombosis when the time of primary $\mathrm{PCl}$ was less than $5 \mathrm{~h}$ from pain to angioplasty.

There are concerns on the propensity for stent thrombosis associated with DES implantation for high-risk patients with ST segment elevation AMI $[19,20]$. The present study showed a potential benefit of the second-generation DES in lowering the risk of definite or probable stent thrombosis during 7 to 18 months after stent implantation. In the current meta-analysis, we reviewed and analyzed the overall incidence of adverse events (early and late thrombosis). The risk of stent thrombosis associated DES implantation was related to early discontinuation of dual antiplatelet therapy [21]. However, in the enrolled trials, aspirin was recommended for life, and clopidogrel for a minimum of 12 months or until the end of the follow-up. It indicated that the profile of antiplatelet therapy had little influence on the incidence of stent thrombosis. Although the influence of procedural and patient characteristics cannot be excluded, it has been suggested that the newer polymer coatings used in second-generation DES, such as the EES, may have anti-inflammatory properties and may be partly responsible for reduction in early or late stent thrombosis. Of note, all the enrolled trials except the KOMER study (reporting 18-month results) [14] provided no more than 12-month follow-up data. Thus, it was appropriate to restrict the findings to a relatively short-term follow-up. Recently, 2-year follow-up data of large randomized allcomer trials including $20 \%$ to $30 \%$ of AMI patients were presented. Very few addi- 
tional stent thromboses were seen between 1 and 2 years in the EES stent arms [22, 23], as well as in a subgroup analysis of $\mathrm{AMI}$ patients who were not separately randomized [24]. Based on the currently available evidence, we did not still confirm the clinical factor influencing the clinical outcome. In the present study, the elderly patients or the subjects receiving primary $\mathrm{PCl}$ within $5 \mathrm{~h}$ from symptoms to angioplasty showed a tendency toward a lower rate of stent thrombosis associated with the second-generation DES. The AMI patients receiving primary $\mathrm{PCl}$ within $5 \mathrm{~h}$ might be characterized by higher risk of thrombotic coronary lesions. On basis of the findings from subgroup analyses, we presumed that there might be a more beneficial effect of the second-generation DES on lowering the risk of stent thrombosis in elderly patients with a higher risk thrombotic coronary lesions. Additionally, in terms of overall estimates, the current study did not find significant differences in prognostic outcomes, such as MACEs and allcause death, between the two generations of DES. However, when the analysis was restricted to the patients receiving the second-generation EES or the subjects aged 60 years or above, episodes of stent thrombosis to impact clinical hard endpoints of MACEs, and there was a similar change tendency observed between the two outcomes. In the PREMIER registry, the use of the first-generation DES significantly increased the risk of mortality within the first 6 months related to early discontinuation of antiplatelet therapy [25]. However, two large studies, TYPHOON and STRATEGY, indicated that DES was able to be used safely in the setting of primary $\mathrm{PCl}$ with an acceptable risk of stent thrombosis [26, 27].

A previous meta-analysis showed that compared to bare-metal stents SES and PES significantly reduced the 2-year incidence of TLR in patients with ST-segment elevation AMI undergoing primary $\mathrm{PCI}$ [28]. However, in the current study the TLR rate in AMI patients undergoing second-generation DES implantation did not significantly differ from that receiving first-generation DES. Of note, among 4 trials enrolled in the analysis of the clinical endpoint, only the KOMER trial [14], comparing clinical efficacy and safety of ZES versus SES and/ or PES in ACS patients, showed the superiority of the first-generation DES. Furthermore, in terms of patients with stable coronary disease undergoing elective $\mathrm{PCl}$, the ENDEAVOR III study [29], a prospective, randomized, single-blinded multicenter trial, comparing ZES and SES, similarly showed higher late lumen loss and binary restenosis associated with the use of ZES at 8-month follow-up. Statistically, the inferiority of ZES was not shown in the subgroup analysis of the present meta-analysis. Nevertheless, ZES had a trend toward a higher TLR rate in comparison with the first-generation DES.

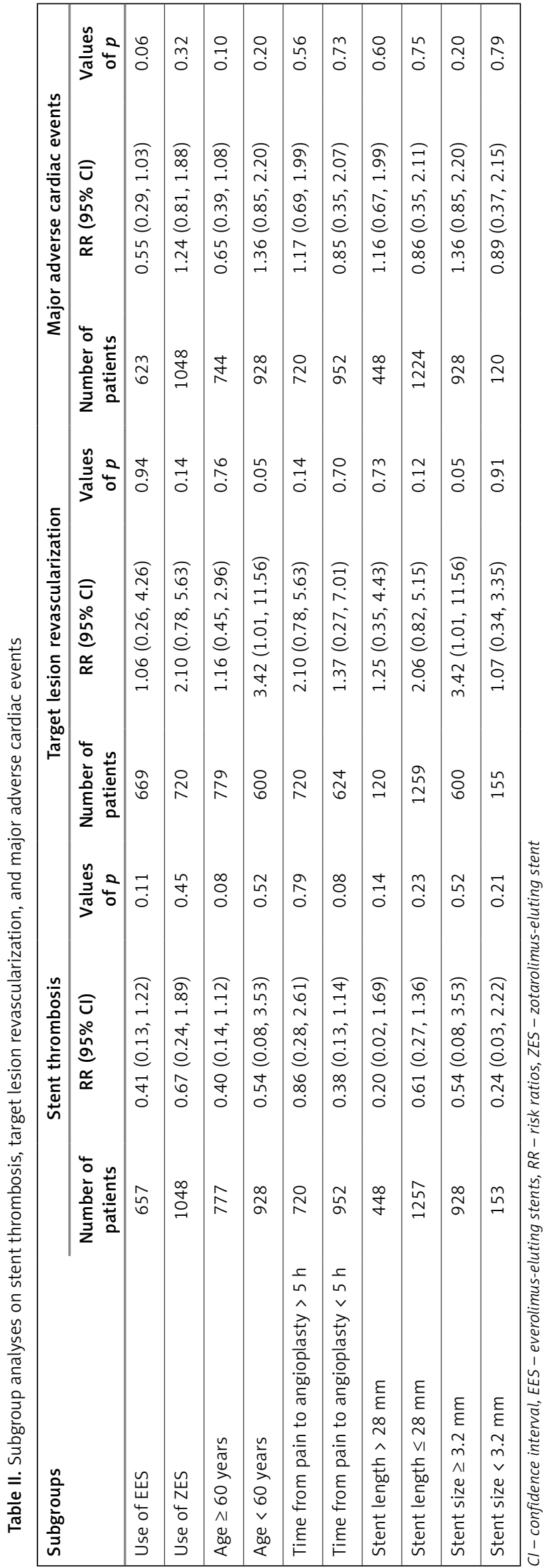




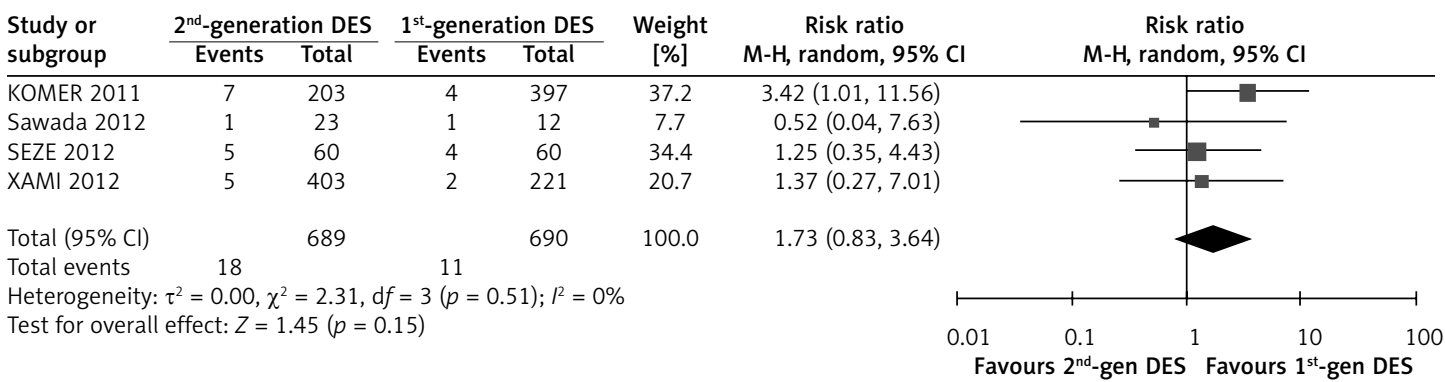

Figure 3. Forest plot of risk ratios of second- versus first-generation drug-eluting stents for TLR $\mathrm{Cl}$ - confidence intervals, DES - drug-eluting stents, $\mathrm{M}-\mathrm{H}$-Mantel-Haenszel

\begin{tabular}{|c|c|c|c|c|c|c|c|c|}
\hline \multirow{2}{*}{$\begin{array}{l}\text { Study or } \\
\text { subgroup }\end{array}$} & \multicolumn{2}{|c|}{$2^{\text {nd }}$-generation DES } & \multicolumn{2}{|c|}{$1^{\text {st }}$-generation DES } & \multirow{2}{*}{$\begin{array}{l}\text { Weight } \\
{[\%]}\end{array}$} & \multirow{2}{*}{$\begin{array}{c}\text { Risk ratio } \\
\mathrm{M}-\mathrm{H} \text {, random, } 95 \% \mathrm{Cl}\end{array}$} & \multirow{2}{*}{\multicolumn{2}{|c|}{$\begin{array}{c}\text { Risk ratio } \\
\mathrm{M}-\mathrm{H} \text {, random, } 95 \% \mathrm{Cl}\end{array}$}} \\
\hline & Events & Total & Events & Total & & & & \\
\hline KOMER 2011 & 14 & 203 & 20 & 397 & 27.0 & $1.37(0.71,2.65)$ & - & \\
\hline SEZE 2012 & 8 & 60 & 9 & 60 & 18.9 & $0.89(0.37,2.15)$ & & \\
\hline XAMI 2012 & 18 & 403 & 18 & 221 & 28.4 & $0.55(0.29,1.03)$ & & \\
\hline ZEST AMI 2009 & 12 & 108 & 18 & 220 & 25.7 & $1.36(0.68,2.72)$ & - & \\
\hline Total $(95 \% \mathrm{Cl})$ & & 774 & & 898 & 100.0 & $0.97(0.61,1.54)$ & & \\
\hline Total events & 52 & & 65 & & & & & \\
\hline \multirow{2}{*}{\multicolumn{6}{|c|}{$\begin{array}{l}\text { Heterogeneity: } \tau^{2}=0.09, \chi^{2}=5.11, \mathrm{~d} f=3(p=0.16) ; I^{2}=41 \% \\
\text { Test for overall effect: } Z=0.13(p=0.90)\end{array}$}} & & & \\
\hline & & & & & & 0.0 & 0.1 & 100 \\
\hline
\end{tabular}

Figure 4. Forest plot of risk ratios of second-versus first-generation drug-eluting stents for MACEs

$\mathrm{Cl}$ - confidence intervals, DES - drug-eluting stents, $\mathrm{M}-\mathrm{H}$-Mantel-Haenszel

\begin{tabular}{|c|c|c|c|c|c|c|c|c|}
\hline \multirow{2}{*}{$\begin{array}{l}\text { Study or } \\
\text { subgroup }\end{array}$} & \multicolumn{2}{|c|}{$2^{\text {nd }}$-generation DES } & \multicolumn{2}{|c|}{$1^{\text {st }}$-generation DES } & \multirow{2}{*}{$\begin{array}{c}\text { Weight } \\
{[\%]}\end{array}$} & \multirow{2}{*}{$\begin{array}{c}\text { Risk ratio } \\
\mathrm{M}-\mathrm{H} \text {, random, } 95 \% \mathrm{Cl}\end{array}$} & \multirow{2}{*}{\multicolumn{2}{|c|}{$\begin{array}{c}\text { Risk ratio } \\
\mathrm{M}-\mathrm{H} \text {, random, } 95 \% \mathrm{Cl}\end{array}$}} \\
\hline & Events & Total & Events & Total & & & & \\
\hline KOMER 2011 & 7 & 203 & 7 & 397 & 43.2 & $1.96(0.701,5.50)$ & 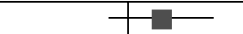 & \\
\hline SEZE 2012 & 1 & 60 & 2 & 60 & 11.8 & $0.50(0.05,5.37)$ & & \\
\hline XAMI 2012 & 8 & 403 & 7 & 221 & 45.0 & $0.63(0.23,1.71)$ & & \\
\hline Total $(95 \% \mathrm{Cl})$ & & 666 & & 678 & 100.0 & $1.00(0.42,2.36)$ & & \\
\hline Total events & 16 & & 16 & & & & & \\
\hline \\
\hline \multirow{2}{*}{\multicolumn{6}{|c|}{ Test for overall effect: $Z=0.00(p=1.00)$}} & 0.01 & 0.1 & 100 \\
\hline & & & & & & \multicolumn{3}{|c|}{ Favours $2^{\text {nd }}$-gen DES Favours $1^{\text {st }}$-gen DES } \\
\hline
\end{tabular}

Figure 5. Forest plot of risk ratios of second-versus first-generation drug-eluting stents for all-cause death

$\mathrm{Cl}$-confidence intervals, DES - drug-eluting stents, $\mathrm{M}-\mathrm{H}$-Mantel-Haenszel

Causally, the non-significant effect of ZES might mainly result from the limited number of study participants. Thus, large-scale clinical studies are required to further confirm the true effect of the second-generation DES on the need for revascularization in patients with AMI. Nevertheless, the use of the second-generation EES did not provide a significant impact on this clinical outcome in AMI settings. That is to say, among the second-generation DES, EES might be recommended with priority in these specific patients undergoing primary $\mathrm{PCl}$. In addition, in the younger patients or those implanted stents of bigger size, the second-generation DES, probably referring to ZES, seemed likely to increase the occurrence of TLR. However, the potential cause was not identified clearly based on the currently available evidence.

Limitations of the meta-analysis deserve comments. The power of the subgroup analyses might be restricted by the limited study number and population size, and the conclusions drawn should be considered carefully. Moreover, inherent in any review process of published studies is the possibility of publication bias. Our search was restricted to studies published in indexed journals. In this meta-analysis, we did not search for unpublished studies or for original data. However, we found no evidence of substantial publication bias. No publication bias as well as the use of a random effects model ensured the robustness of conclusions in the meta-analysis. Moreover, the sensitivity analyses further confirmed the credibility of the majority of pooled estimates.

In conclusion, based on the available data from RCTs, the present meta-analysis demonstrated that the second-generation DES appeared to lower the risk of stent thrombosis in AMI patients with a highly thrombotic environment compared with the first-generation DES. However, no significant intergroup differences in TLR, MACEs, or all-cause mortality were found. In addition, there might be a lower incidence of MACEs associated 
with the second-generation EES. Moreover, in elderly patients the second-generation DES showed a trend toward reduced incidence of MACEs and stent thrombosis in patients with AMI. These observations suggested that the second-generation DES, especially EES, might achieve a recommendation with priority in AMI patients.

\section{Acknowledgments}

This work was supported by a project of the Institute of Gerontology of Jilin province, a project of the Education Department of Jilin province, and a project of the Department of Science and Technology of Jilin province (200705172).

\section{References}

1. Li Q, Tong Z, Wang L, et al. Efficacy and safety of a biodegradable polymer sirolimus-eluting stent in primary percutaneous coronary intervention: a randomized controlled trial. Arch Med Sci 2013; 9: 1040-8.

2. Dzielińska Z, Małek LA, Januszewicz A, et al. Adrenomedullin concentrations at two time points following myocardial infarction and prediction of mid-term outcomes. Arch Med Sci 2011; 7: 971-6.

3. Piccolo R, Cassese $S$, Galasso G, et al. Long-term clinical outcomes following sirolimus-eluting stent implantation in patients with acute myocardial infarction. A meta-analysis of randomized trials. Clin Res Cardiol 2012; 101: 885-93.

4. Lagerqvist B, James SK, Stenestrand U, et al. Long-term outcomes with drug-eluting stents versus bare-metal stents in Sweden. N Engl J Med 2007; 356: 1009-19.

5. Daemen J, Wenaweser P, Tsuchida K, et al. Early and late coronary stent thrombosis of sirolimus-eluting and paclitaxel-eluting stents in routine clinical practice: data from a large two-institutional cohort study. Lancet 2007; 369: 667-78.

6. De Luca G, Dirksen MT, Spaulding C, et al. Drug-eluting vs bare-metal stents in primary angioplasty: a pooled patient-level meta-analysis of randomized trials. Arch Intern Med 2012; 172: 611-21.

7. Uematsu M, Akashi YJ, Ashikaga K, et al. Association between heart rate at rest and myocardial perfusion in patients with acute myocardial infarction undergoing cardiac rehabilitation - a pilot study. Arch Med Sci 2012; 8: 622-30.

8. Kleinbongard P, Bose D, Konorza T, et al. Acute vasomotor paralysis and potential downstream effects of paclitaxel from stents implanted for saphenous vein aorto-coronary bypass stenosis. Basic Res Cardiol 2011; 106: 681-9.

9. Stone GW, Rizvi A, Newman W, et al. Everolimus-eluting versus paclitaxel-eluting stents in coronary artery disease. N Engl J Med 2010; 362: 1663-74.

10. Kedhi E, Joesoef KS, McFadden E, et al. Second-generation everolimus-eluting and paclitaxel-eluting stents in real-life practice (COMPARE): a randomised trial. Lancet 2010; 375: 201-9.

11. Palmerini T, Biondi-Zoccai G, Della Riva D, et al. Stent thrombosis with drug-eluting and bare-metal stents: evidence from a comprehensive network meta-analysis. Lancet 2012; 379: 1393-402.
12. Yan P, Dong P, Li Z. Second-versus first-generation drug-eluting stents for diabetic patients: a meta-analysis. Arch Med Sci 2014; 10: 213-21.

13. Higgins JP, Thompson SG, Deeks JJ, et al. Measuring inconsistency in meta-analyses. BMJ 2003; 327: 557-60.

14. Kang WC, Ahn T, Lee K, et al. Comparison of zotarolimus-eluting stents versus sirolimus-eluting stents versus paclitaxel-eluting stents for primary percutaneous coronary intervention in patients with ST-elevation myocardial infarction: results from the Korean Multicentre Endeavor (KOMER) acute myocardial infarction (AMI) trial. Eurolntervention 2011; 7: 936-43.

15. Sawada T, Shinke T, Otake H, et al. Comparisons of detailed arterial healing response at seven months following implantation of an everolimus- or sirolimus-eluting stent in patients with ST-segment elevation myocardial infarction. Int J Cardiol 2013; 168: 960-6.

16. Chung WY, Kang J, Cho YS, et al. A randomized, prospective, two-center comparison of sirolimus-eluting stent and zotarolimus-eluting stent in acute ST-elevation myocardial infarction: the SEZE trial. Chin Med J (Engl) 2012; 125: 3373-81.

17. Hofma SH, Brouwer J, Velders MA, et al. Second-generation everolimus-eluting stents versus first-generation sirolimus-eluting stents in acute myocardial infarction. 1 -year results of the randomized XAMI (XienceV Stent vs. Cypher Stent in Primary PCI for Acute Myocardial Infarction) trial. J Am Coll Cardiol 2012; 60: 381-7.

18. Lee CW, Park DW, Lee SH, et al. Comparison of the efficacy and safety of zotarolimus-, sirolimus-, and paclitaxel-eluting stents in patients with ST-elevation myocardial infarction. Am J Cardiol 2009; 104: 1370-6.

19. Kaltoft A, Kelbaek H, Thuesen L, et al. Long-term outcome after drug-eluting versus bare-metal stent implantation in patients with ST-segment elevation myocardial infarction: 3-year follow-up of the randomized DEDICATION (Drug Elution and Distal Protection in Acute Myocardial Infarction) Trial. J Am Coll Cardiol 2010; 56: 641-5.

20. Vink MA, Dirksen MT, Suttorp MJ, et al. 5-year follow-up after primary percutaneous coronary intervention with a paclitaxel-eluting stent versus a bare-metal stent in acute ST-segment elevation myocardial infarction: a follow-up study of the PASSION (Paclitaxel-Eluting Versus Conventional Stent in Myocardial Infarction with ST-Segment Elevation) trial. JACC Cardiovasc Interv 2011; 4: 24-9.

21. Spertus JA, Kettelkamp R, Vance C, et al. Prevalence, predictors, and outcomes of premature discontinuation of thienopyridine therapy after drug eluting stent placement: results from the PREMIER registry. Circulation 2006; 113: 2803-9.

22. Silber $\mathrm{S}$, Windecker $\mathrm{S}$, Vranckx P, et al. Unrestricted randomised use of two new generation drug-eluting coronary stents: 2-year patient-related versus stent-related outcomes from the RESOLUTE All Comers trial. Lancet 2011; 377: 1241-7.

23. Smits PC, Kedhi E, Royaards KJ, et al. 2-year follow-up of a randomized controlled trial of everolimus- and paclitaxel-eluting stents for coronary revascularization in daily practice. COMPARE (Comparison of the everolimus eluting XIENCE-V stent with the paclitaxel eluting TAXUS LIBERTE stent in all-comers: a randomized open label trial). J Am Coll Cardiol 2011; 58: 11-8.

24. Kedhi E, Gomes M, Joesoef KS, et al. Everolimus-eluting stents and paclitaxel-eluting stents in patients presenting with myocardial infarction: insights from the twoyear results of the COMPARE prospective randomised controlled trial. Eurolntervention 2012; 7: 1376-85. 
25. Spertus JA, Kettelkamp R, Vance C, et al. Prevalence, predictors, and outcomes of premature discontinuation of thienopyridine therapy after drug-eluting stent placement: results from the PREMIER registry. Circulation 2006; 113: 2803-9.

26. Steg PG, Fox KA, Eagle KA, et al. Mortality following placement of drug-eluting and bare-metal stents for ST-segment elevation acute myocardial infarction in the Global Registry of Acute Coronary Events. Eur Heart J 2009; 30: 321-9.

27. Valgimigli M, Campo G, Percoco G, et al. Comparison of angioplasty with infusion of tirofiban or abciximab and with implantation of sirolimus-eluting or uncoated stents for acute myocardial infarction: the MULTISTRATEGY randomized trial. JAMA 2008; 299: 1788-99.

28. De Luca G, Stone GW, Suryapranata H, et al. Efficacy and safety of drug-eluting stents in ST-segment elevation myocardial infarction: a meta-analysis of randomized trials. Int J Cardiol 2009; 133: 213-22.

29. Kandzari DE, Leon MB, Popma JJ, et al. Comparison of zotarolimus-eluting and sirolimus-eluting stents in patients with native coronary artery disease: a randomized controlled trial. J Am Coll Cardiol 2006; 48: 2440-7. 